\title{
Fluxo difusivo de fósforo em função de doses e da umidade do solo ${ }^{1}$
}

\author{
José P. V. da Costa ${ }^{2}$, Nairam F. de Barros ${ }^{3}$, Abel W. de Albuquerque², Gilson Moura Filho ${ }^{2} \&$ José R. Santos ${ }^{2}$
}

\begin{abstract}
RESUMO
A difusão é o mecanismo mais expressivo do transporte do fósforo no solo e depende de vários fatores, como o conteúdo volumétrico de água, a interação fósforo-colóide do solo, a distância da fonte às raízes, o teor e a temperatura do solo. Avaliaram-se os efeitos do conteúdo volumétrico de água e de doses de fósforo no seu fluxo difusivo no solo, em amostras da camada superficial de cinco solos. O experimento consistiu do arranjo fatorial $5 \times 8 \times 5$, referente a cinco materiais de solo, oito níveis de umidade e cinco doses de fósforo, dispostos em blocos ao acaso, com quatro repetições. Como unidade experimental foram utilizados anéis de PVC com volume útil de $360 \mathrm{~cm}^{3}$, que serviram como câmara de difusão. Para avaliação do fluxo difusivo de fósforo nas amostras foram utilizadas lâminas de resina de troca aniônica (IONICS 204UZRA). Pelos resultados, constatou-se que o fluxo difusivo sofre influência da umidade do solo e das doses de fósforo aplicadas.
\end{abstract}

Palavras-chave: água, mobilidade de nutriente, difusão de nutriente

\section{Influence of phosphorus doses and soil moisture on diffusion flow}

\begin{abstract}
The main phosphorus transport mechanism in the soil is diffusion, which is influenced by several soil factors, such as volumetric water content, phosphorus-colloid interaction, distance between source and roots, content and temperature. The effects of the soil water content and phosphorus doses on the diffusion flow into soil were assessed in samples from the superficial layers of five soils. The treatments were arranged in a $5 \times 8 \times 5$ factorial design corresponding, respectively, to five soils, eight moisture levels and five phosphorus doses. A completely randomized block design with four replications was used. The experimental unit was a PVC ring with a volume of $360 \mathrm{~cm}^{3}$, which acted as a diffusion chamber. Anionic exchange resin slides (IONICS 204UZRA) were utilized to assess the phosphorus diffusion flow. Results indicated that the diffusion flow was influenced by phosphorus doses and moisture content.
\end{abstract}

Key words: water, nutrient mobility, nutrient diffusion 


\section{INTRODUÇÃO}

Os solos das regiões tropicais quase sempre apresentam elevada capacidade de adsorção e baixos teores de fósforo, o que torna a nutrição fosfatada fator limitante à obtenção de rendimentos agrícolas economicamente satisfatórios. A disponibilidade do fósforo aplicado como fertilizantes é, em geral, limitada, em razão da abundância de óxidos de ferro e de alumínio nesses solos. Várias reações estão envolvidas nesta limitação de disponibilidade, como a precipitação (formação de nova fase ou composto definido), a adsorção (reação na interface sólido/solução) e a difusão nas imperfeições dos cristais (Parfitt, 1989; Almeida et al., 2003).

Os atributos do solo, o transporte do nutriente no solo, a morfologia, a fisiologia do sistema radicular e a microbiota da rizosfera são fatores diretamente relacionados à absorção de fósforo pela planta. Nesse sentido, o conhecimento desses torna-se imprescindível para melhor entendimento dos mecanismos envolvidos na interação solo-planta que determinam a absorção do nutriente pela planta e para adoção de práticas de adubação.

O principal mecanismo de transporte do fósforo no solo é a difusão, que é influenciada por vários fatores, tais como: o conteúdo volumétrico de água no solo, a interação fósforo-colóide do solo, a distância a percorrer até as raízes, o teor do elemento e a temperatura do solo. Em geral, são registrados valores muito baixos de transporte de fósforo, em razão de sua forte interação com os colóides do solo, especialmente em solos tropicais muito intemperizados; assim, a baixa mobilidade do nutriente se tem constituído num problema para a nutrição fosfatada das culturas (Parfitt, 1989; Kampf \& Cury, 2003; Azevedo et al., 2004).

Pela primeira lei de Fick, a relação entre o fluxo difusivo de um soluto em uma solução pura, o gradiente de concentração e o coeficiente de difusão é expressa por:

$$
\mathrm{F}=-\mathrm{DdC} / \mathrm{dx}
$$

$$
\begin{array}{cl}
\text { em que } & \\
\text { F } & \text { - fluxo difusivo do soluto }\left(\mathrm{mol} \mathrm{cm}-2 \mathrm{~s}^{-1}\right) \\
\mathrm{D} & \text { - coeficiente de difusão do soluto }\left(\mathrm{cm}^{2} \mathrm{~s}^{-1}\right) \\
\mathrm{dC} / \mathrm{dx} & \text { - gradiente de concentração }\left(\mathrm{mol} \mathrm{cm}-3 \mathrm{~cm}^{-1}\right)
\end{array}
$$

Uma maior tortuosidade do trajeto a ser percorrido pelos elementos e as interações existentes entre eles e as partículas do solo implicarão em um menor coeficiente de difusão efetivo dos nutrientes no solo em relação ao expressado na equação.

Adaptando-se a lei de Fick para solos, a difusão do fósforo pode ser quantificada pela seguinte expressão matemática (Nye \& Tinker, 1977; Barber, 1995; Novais \& Smyth, 1999)):

$$
\mathrm{D}=\mathrm{D}_{1} \mathrm{qf} \mathrm{f}_{1}\left(\mathrm{dC}_{1} / \mathrm{dC}\right)
$$

donde D é o coeficiente de difusão de fósforo no solo, em $\mathrm{cm}^{2} \mathrm{~s}^{-1} ; \mathrm{D}_{1}$ é o coeficiente de difusão de fósforo em água $\left(0,89 \times 10^{-5} \mathrm{~cm}^{2} \mathrm{~s}^{-1}\right.$, a $\left.25^{\circ} \mathrm{C}\right)$; q é o conteúdo volumétrico de água no solo, em $\mathrm{cm}^{3} \mathrm{~cm}^{-3} ; \mathrm{f}_{1}$ é o fator de impedância, adi- mensional; $\mathrm{C}_{1}$ é a concentração de $\mathrm{P}$ na solução do solo ou fator intensidade (I), em mol cm$~^{-3}$; e $\mathrm{C}$ é a concentração de fósforo adsorvido-lábil ou fator quantidade (Q), em $\mathrm{mol} \mathrm{cm}^{-3}$.

A diferencial $\mathrm{dC}_{\mathrm{l}} / \mathrm{dC}$ é o inverso do fator capacidade do solo $(\mathrm{dQ} / \mathrm{dI})$. O fator de impedância, $\mathrm{f}_{1}$, depende, fundamentalmente, da tortuosidade do caminho seguido pelo soluto através dos poros. Outras causas podem ser nele incluídas, tais como a redução do gradiente de concentração ao longo desta distância e o aumento da viscosidade da água próximo à superfície das partículas sólidas do solo, afetando a mobilidade dos solutos. Tais razões reduzem a difusão de íons.

De acordo com a Eq.2, existe uma relação direta entre o coeficiente de difusão de fósforo no solo e o conteúdo volumétrico de água. Quando a umidade aumenta, o filme de água próximo às partículas sólidas do solo fica mais espesso, diminuindo a interação íon-colóide. O fator de impedância também aumenta como conseqüência da diminuição da tortuosidade e da viscosidade da água, que apresentará valores mais próximos daqueles da água pura, em razão da maior distância entre seus íons e os colóides do solo. Esta relação direta entre o conteúdo de água do solo e a difusão de fósforo, tem sido registrada por vários autores ( Remer \& Schilling, 1981; Ruiz, 1986a; Novais \& Smyth, 1999). Para Barber (1995), o incremento do conteúdo de água do solo exerce efeito indireto sobre o transporte, devido ao aumento do fator de impedância como conseqüência da redução da tortuosidade do trajeto a ser percorrido pelo fósforo. Por outro lado, Ruiz (1986b) associa este efeito à redução da viscosidade da solução do solo, que apresentaria valores mais próximos aos da água pura; Contudo, em alguns solos tropicais se tem observado que a quantidade de fósforo absorvida pelas plantas reduz drasticamente ainda em condições de umidade relativamente elevada, o que permite questionar a proporcionalidade direta entre o conteúdo de água do solo e a difusão de fósforo, indicada pela Eq.2.

Neste trabalho se objetivou avaliar o efeito de diferentes níveis de umidade e de doses de fósforo sobre o fluxo difusivo deste elemento, em amostras de solos.

\section{MATERIAL E MÉTODOS}

\section{Caracterização dos solos}

O ensaio foi desenvolvido em laboratório, utilizando-se amostras da camada de $0-20 \mathrm{~cm}$ de profundidade de cinco solos do Estado de Minas Gerais (EMBRAPA, 1999): Latossolo Vermelho, textura média $\left(\mathrm{LV}_{1}\right)$ - Três Marias, Latossolo Vermelho-Amarelo textura média $\left(\mathrm{LVA}_{1}\right)$ - Três Marias, Latossolo Vermelho distroférrico, textura argilosa (LVdf) - São Sebastião do Paraíso, Latossolo Vermelho-Amarelo, textura argilosa $\left(\mathrm{LVA}_{2}\right)$ - Ponte Nova e Latossolo Vermelho, textura muito argilosa $\left(\mathrm{LV}_{2}\right)$ - Sete Lagoas. As amostras foram secadas ao ar, destorroadas, passadas em peneira de malha de $2 \mathrm{~mm}$ de abertura e homogeneizadas, retirando-lhes, em seguida, subamostras para caracterização física, química e mineralógica (Tabela 1 e Figura 1). 
Tabela 1. Valores médios dos atributos químicos e físicos das amostras dos solos

\begin{tabular}{|c|c|c|c|c|c|}
\hline Atributos & LV1 & LVA1 & LVdf & LVA2 & $\overline{\text { LV2 }}$ \\
\hline $\mathrm{pH}$ em $\mathrm{H}_{2} \mathrm{O}(1: 2,5)$ & 5,4 & 5,1 & 4,7 & 5,2 & 4,7 \\
\hline $\mathrm{pH}$ em KCl $(1: 2,5)$ & 4,2 & 3,8 & 4,1 & 4,1 & 4,0 \\
\hline $\left.\mathrm{Al}^{3+}(\mathrm{cmolc} \mathrm{dm})^{-3}\right)^{(1)}$ & 0,75 & 0,91 & 0,54 & 0,43 & 1,22 \\
\hline $\mathrm{Ca}^{2+}\left(\mathrm{cmolc} \mathrm{dm}^{-3}\right)^{(1)}$ & 0,05 & 0,22 & 0,50 & 0,50 & 0,94 \\
\hline $\mathrm{Mg}^{2+}\left(\mathrm{cmolc} \mathrm{dm}^{-3}\right)^{(1)}$ & 0,04 & 0,37 & 0,20 & 0,03 & 0,21 \\
\hline 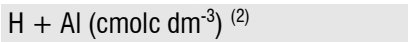 & 3,89 & 3,98 & 7,20 & 5,52 & 14,54 \\
\hline $\mathrm{P}\left(\mathrm{mg} \mathrm{dm}^{-3}\right)^{(3)}$ & 0,7 & 1,3 & 1,9 & 0,7 & 1,3 \\
\hline $\mathrm{K}\left(\mathrm{mg} \mathrm{dm}^{-3}\right)^{(3)}$ & 10 & 15 & 20 & 16 & 23 \\
\hline Carbono orgânico $\left(\text { dag kg }^{-1}\right)^{(4)}$ & 0,53 & 1,49 & 1,70 & 1,94 & 2,13 \\
\hline P-remanescente $\left(\mathrm{mg} \mathrm{L}^{-1}\right)^{(5)}$ & 40,0 & 16,1 & 6,1 & 5,2 & 5,2 \\
\hline $\operatorname{CMAP}\left(\mathrm{mg} \mathrm{dm}^{-3} \mathrm{P}\right)^{(6)}$ & 399 & 744 & 1,112 & 1,170 & 1,172 \\
\hline $\operatorname{EAP}\left(\mathrm{mg} \mathrm{dm}^{-3} \mathrm{P}\right)^{-1}(7)$ & 0,868 & 0,580 & 0,956 & 0,657 & 1,240 \\
\hline CTC efetiva (cmolc $\mathrm{kg}^{-1}$ ) & 0,87 & 1,54 & 1,29 & 1,00 & 2,37 \\
\hline CTC total $\left(\mathrm{cmolc} \mathrm{kg}^{-1}\right)$ & 4,01 & 4,61 & 7,95 & 6,09 & 15,75 \\
\hline $\mathrm{m}(\%)^{(8)}$ & 86,2 & 59,1 & 41,9 & 43,0 & 51,5 \\
\hline Capacidade de campo (dag k & 15,4 & 19,3 & 26,0 & 36,0 & 36,7 \\
\hline Areia grossa $\left(\text { dag } \mathrm{kg}^{-1}\right)^{(10)}$ & 32 & 45 & 6 & 20 & 9 \\
\hline Areia fina $\left(\mathrm{dag} \mathrm{kg}^{-1}\right)^{(10)}$ & 51 & 15 & 25 & 12 & 5 \\
\hline Silte $\left(\text { dag } \mathrm{kg}^{-1}\right)^{(10)}$ & 4 & 7 & 23 & 12 & 10 \\
\hline Argila $\left(\text { dag } \mathrm{kg}^{-1}\right)^{(10)}$ & 13 & 33 & 49 & 56 & 76 \\
\hline Densidade Aparente $\left(\mathrm{g} \mathrm{cm}^{-3}\right)^{(11)}$ & 1,38 & 1,30 & 1,22 & 1,17 & 1,00 \\
\hline Densidade de Partículas $\left(\mathrm{g} \mathrm{cm}^{-3}\right)^{(12)}$ & 2,63 & 2,63 & 3,03 & 2,73 & 2,63 \\
\hline Porosidade (\%) & 48 & 51 & 60 & 57 & 62 \\
\hline \multicolumn{6}{|c|}{ 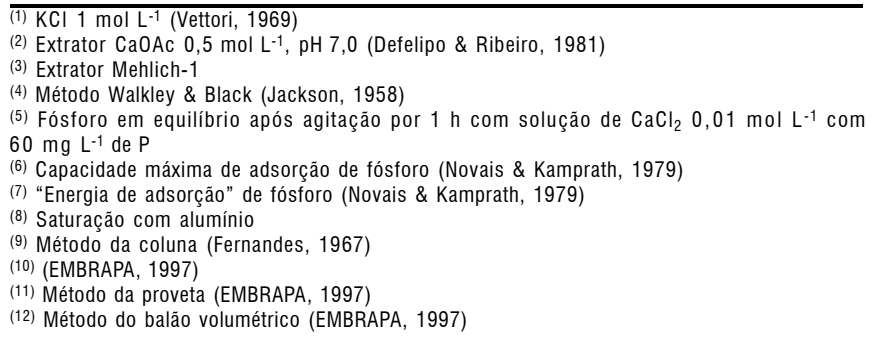 } \\
\hline
\end{tabular}

\section{Delineamento experimental e montagem do experimento}

$\mathrm{O}$ ensaio consistiu de um arranjo fatorial $5 \times 8 \times 5$ correspondendo, respectivamente, a cinco solos, oito níveis de umidade e cinco doses de fósforo. Os tratamentos, com quatro repetições, foram dispostos em blocos casualizados. Como unidade experimental, se utilizaram anéis de PVC com $5 \mathrm{~cm}$ de altura e $10 \mathrm{~cm}$ de diâmetro interno e um volume útil de $360 \mathrm{~cm}^{3}$, que serviram como câmara de difusão.

As doses de fósforo corresponderam a 0, 25, 50, 75 e 100\% da capacidade máxima de adsorção de fósforo (CMAP) dos solos, e os níveis de umidade, a 10, 20, 40, 60, 70, 80, 90 e $100 \%$ da porosidade total dos solos. O fósforo foi aplicado ao solo via solução, utilizando-se como fonte o fosfato de potássio monobásico $\left(\mathrm{KH}_{2} \mathrm{PO}_{4}\right)$. As amostras foram acondicionadas em sacos de plástico e incubadas pelo período de 15 dias, com teor de água do solo elevado a $80 \%$ da capacidade de campo, com a finalidade de promover o equilíbrio do elemento com o solo. Decorrido esse período, as amostras foram secadas, destorroadas, passadas em peneira de malha de $2 \mathrm{~mm}$ de abertura e transferidas para a câmara de difusão. Os anéis de PVC tiveram o fundo fechado com lâmina de isopor de 1,2 cm de espessura, fixada com fita de polietileno, e, após receberem os tratamentos, foram cobertos com plástico, para evitar perda de água (Villani, 1995).

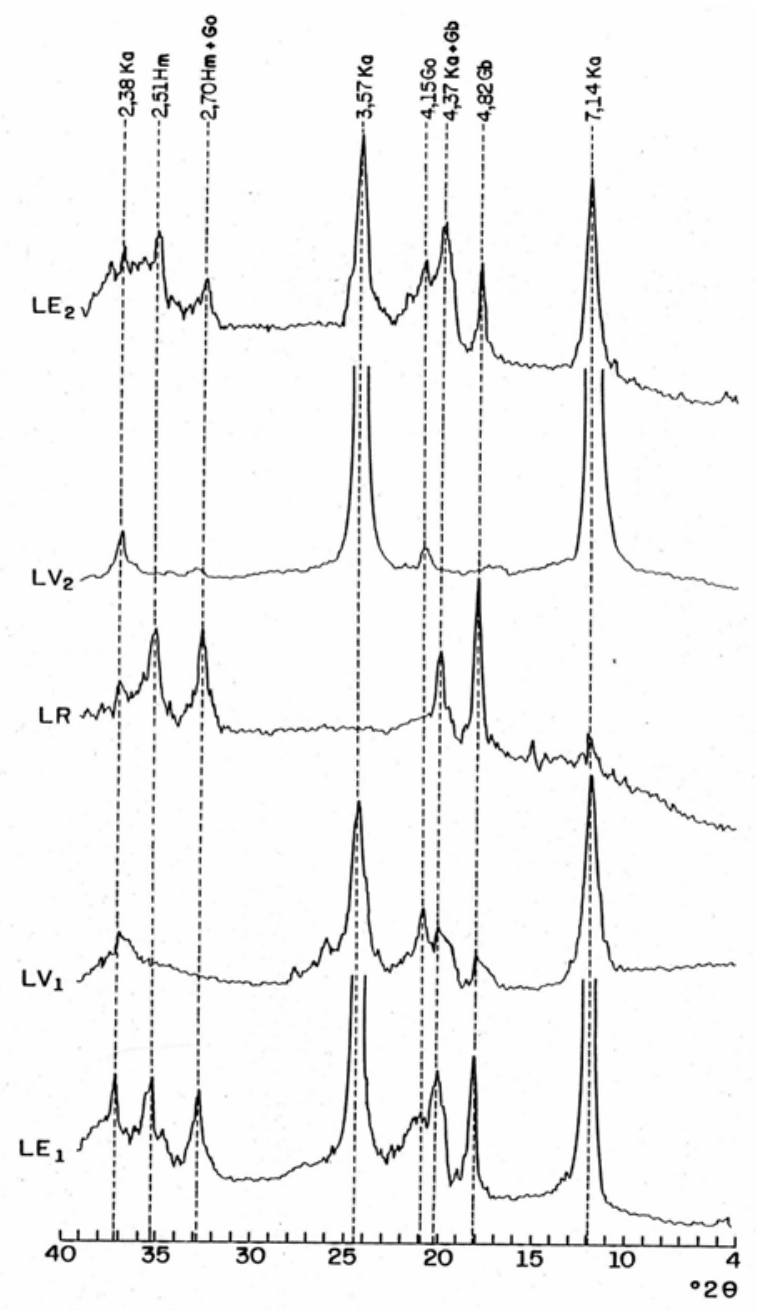

Figura 1. Difratogramas de raios- $X$ da fração argila em lâminas orientadas de amostras dos solos estudados. Radiação Cu - Ka . Ka - caulinita; Hm - hematita; Go - goethita; Gb - gibbsita

Para avaliação do fluxo difusivo de fósforo no solo, utilizaram-se lâminas de resina de troca aniônica (IONICS 204UZRA) as quais, antes de serem utilizadas, foram submetidas a pré-condicionamento para fósforo, utilizando-se uma solução saturada com o elemento $\left(\mathrm{KH}_{2} \mathrm{PO}_{4}\right)$, durante três semanas, fazendo-se todo o tratamento para uso, conforme Raij et al. (1987). Inicialmente, cada câmara de difusão recebeu metade do volume de solo das amostras com os tratamentos correspondentes às doses de fósforo. A lâmina de resina, com área de $10 \mathrm{~cm}^{2}(5 \times 2 \mathrm{~cm})$ e espessura de $0,57 \mathrm{~mm}$, foi disposta horizontalmente e o volume restante do solo foi colocado na câmara. Os tratamentos referentes aos níveis de umidade foram, então, aplicados. Para os tratamentos correspondentes aos níveis de umidade mais baixos, aplicou-se a água e se promoveu uma homogeneização do solo, em saco plástico, antes de levá-lo à câmara de difusão. Para os níveis mais elevados, a água foi aplicada diretamente na câmara de difusão. Nesses tratamentos, houve necessidade da vedação do anel com isopor, com cola, para evitar vazamento de água.

O trabalho foi conduzido em condições de laboratório, com temperatura controlada a $25 \pm 3{ }^{\circ} \mathrm{C}$ por 15 dias; após este período, as lâminas foram retiradas e lavadas com jato de água, 
para remoção do solo aderido e o excesso de água foi retirado com papel-filtro.

\section{Avaliação do fluxo difusivo}

O fósforo adsorvido pela lâmina de resina foi extraído pela agitação da membrana com $50 \mathrm{~mL}$ de uma solução de $\mathrm{NH}_{4} \mathrm{Cl}$ $0,8 \mathrm{~mol} \mathrm{~L}^{-1}+\mathrm{HCl} 0,2 \mathrm{~mol} \mathrm{~L}^{-1}$ durante uma hora, em agitador horizontal, a 270 rotações por minuto, através da metodologia descrita por Raij et al. (1987). A concentração de fósforo foi determinada segundo Braga \& Defelipo (1974). A estimativa da difusão (fluxo difusivo) foi realizada pela quantificação do fósforo adsorvido às lâminas, que correspondeu ao fósforo que atingiu a resina por centímetro quadrado, no período de 15 dias.

Além das análises de variância para cada solo, realizaramse análises de regressão ajustando-se equações para valores de fluxo difusivo de fósforo como variável dependente de níveis de umidade e de doses de fósforo.

\section{RESULTADOS E DISCUSSÃO}

De modo geral, o fluxo difusivo aumentou com as doses de fósforo e com os conteúdos de água utilizados nos cinco solos estudados (Tabela 2). O tratamento com a maior dose de fósforo e o maior conteúdo de água foi o que promoveu o maior valor de fluxo difusivo, em todos os solos.

Quando se fixa dC/dx na Eq.1, o fluxo difusivo passa a ser função do coeficiente de difusão do nutriente no solo, que, por sua vez, está relacionado ao coeficiente de difusão do elemento na água, ao conteúdo volumétrico de água, ao fator de impedância e ao inverso do fator capacidade (dI/dQ). Quando se adicionou fósforo ao solo, o fluxo difusivo aumentou com o acréscimo de dc/dx, e o coeficiente de difusão apresentou maior valor, como conseqüência do aumento de dI/ dQ. Esta diferencial, que é uma medida do inverso do fator capacidade de $\mathrm{P}$ do solo $(\mathrm{dQ} / \mathrm{dI})$, representa o gradiente de concentração de P na Eq.2, que é necessário para a ocorrência do fluxo difusivo.

A variação na umidade do solo influenciou o fator de impedância, pela diminuição da tortuosidade e, conseqüentemente, refletiu-se na variação do coeficiente de difusão e do fluxo difusivo em todos os solos, reduzindo-o significativamente nos níveis de umidade mais baixos, mas se observou que, nos solos com alto fator capacidade de fósforo, o fluxo difusivo sofreu restrições mesmo com doses de P e conteúdos de água elevados. Nos solos com elevado fator capacidade de $\mathrm{P}$, a relação $\mathrm{dI} / \mathrm{dQ}$ pode permanecer constante para as doses de $\mathrm{P}$ normalmente aplicadas, já que a relação entre I e Q é linear para essas doses de P usadas como fertilizante, nesses solos. Não havendo alterações em dI/dQ, o coeficiente de difusão também não será alterado (Novais \& Smyth , 1999; Nunes et al., 2004).

\section{Efeito das doses de fósforo no fluxo difusivo}

O fluxo difusivo de fósforo aumentou nos solos com o incremento da dose do elemento aplicado nos níveis de umidade utilizados (Tabelas 2 e 3). Quando se aumentou a dose de
Tabela 2. Fluxo difusivo de fósforo nos solos influenciado por níveis de umidade e por níveis de fósforo

\begin{tabular}{|c|c|c|c|c|c|c|}
\hline \multirow{3}{*}{ Solo } & \multirow{3}{*}{$\begin{array}{c}\text { Níveis } \\
\text { de umid. }{ }^{(1)} \\
\%\end{array}$} & \multicolumn{5}{|c|}{ Níveis de fósforo(2) } \\
\hline & & 0 & 25 & 50 & 75 & 100 \\
\hline & & \multicolumn{5}{|c|}{$\mu \mathrm{mol} \mathrm{cm}^{-2} / 15$ dias } \\
\hline \multirow{8}{*}{$\mathrm{LV}_{1}$} & 10 & 0,0000 & 0,0143 & 0,1077 & 0,1556 & 0,1907 \\
\hline & 20 & 0,0029 & 0,1674 & 0,4169 & 0,5169 & 0,6077 \\
\hline & 40 & 0,0072 & 0,2427 & 0,5161 & 0,6492 & 0,9242 \\
\hline & 60 & 0,0087 & 0,2960 & 0,6129 & 0,7230 & 1,2940 \\
\hline & 70 & 0,0087 & 0,4423 & 0,8161 & 0,8133 & 1,5121 \\
\hline & 80 & 0,0115 & 0,5077 & 0,9129 & 1,0690 & 1,8758 \\
\hline & 90 & 0,0132 & 0,5952 & 0,9020 & 1,2520 & 2,0415 \\
\hline & 100 & 0,0131 & 0,6399 & 1,1468 & 1,5835 & 2,0891 \\
\hline \multirow{8}{*}{$\mathrm{LVA}_{1}$} & 10 & 0,0015 & 0,0147 & 0,0161 & 0,0548 & 0,0762 \\
\hline & 20 & 0,0029 & 0,1190 & 0,0891 & 0,1831 & 0,5089 \\
\hline & 40 & 0,0058 & 0,3778 & 0,3133 & 0,9008 & 1,9782 \\
\hline & 60 & 0,0072 & 0,6355 & 0,6956 & 2,5887 & 3,2093 \\
\hline & 70 & 0,0072 & 0,6544 & 1,3327 & 3,1935 & 4,2911 \\
\hline & 80 & 0,0129 & 0,8218 & 2,4948 & 3,9210 & 4,6649 \\
\hline & 90 & 0,0161 & 0,9198 & 2,8379 & 4,5633 & 5,1988 \\
\hline & 100 & 0,0145 & 1,1983 & 3,7048 & 5,2827 & 5,9484 \\
\hline \multirow{8}{*}{ LVdf } & 10 & 0,0015 & 0,0057 & 0,0113 & 0,0210 & 0,0210 \\
\hline & 20 & 0,0058 & 0,0207 & 0,0626 & 0,0306 & 0,0722 \\
\hline & 40 & 0,0101 & 0,0915 & 0,0996 & 0,0617 & 0,1343 \\
\hline & 60 & 0,0115 & 0,1105 & 0,1145 & 0,1125 & 0,1988 \\
\hline & 70 & 0,0118 & 0,1681 & 0,2133 & 0,1427 & 0,4282 \\
\hline & 80 & 0,0133 & 0,2101 & 0,3000 & 0,3649 & 0,5633 \\
\hline & 90 & 0,0308 & 0,2899 & 0,3798 & 0,4992 & 0,7573 \\
\hline & 100 & 0,0274 & 0,3355 & 0,4153 & 0,6044 & 0,7565 \\
\hline \multirow{8}{*}{$\mathrm{LVA}_{2}$} & 10 & 0,0015 & 0,0161 & 0,0307 & 0,0641 & 0,1129 \\
\hline & 20 & 0,0044 & 0,0637 & 0,0863 & 0,2177 & 0,2815 \\
\hline & 40 & 0,0085 & 0,1451 & 0,3726 & 0,7060 & 0,8984 \\
\hline & 60 & 0,0085 & 0,2742 & 0,4230 & 0,8371 & 0,9988 \\
\hline & 70 & 0,0113 & 0,3581 & 0,5206 & 0,9794 & 1,1984 \\
\hline & 80 & 0,0131 & 0,3492 & 0,8786 & 1,1823 & 1,4077 \\
\hline & 90 & 0,0226 & 0,5093 & 0,9746 & 1,2472 & 1,5806 \\
\hline & 100 & 0,0177 & 0,6403 & 1,1435 & 1,6863 & 1,7238 \\
\hline \multirow{8}{*}{$\mathrm{LV}_{2}$} & 10 & 0,0044 & 0,0044 & 0,0085 & 0,0145 & 0,0210 \\
\hline & 20 & 0,0058 & 0,0226 & 0,0774 & 0,1355 & 0,1685 \\
\hline & 40 & 0,0058 & 0,0673 & 0,1185 & 0,2718 & 0,2629 \\
\hline & 60 & 0,0099 & 0,0974 & 0,1698 & 0,3222 & 0,3129 \\
\hline & 70 & 0,0099 & 0,1327 & 0,1976 & 0,4726 & 0,4867 \\
\hline & 80 & 0,0145 & 0,1556 & 0,2431 & 0,5339 & 0,5613 \\
\hline & 90 & 0,0226 & 0,2262 & 0,2992 & 0,5845 & 0,6327 \\
\hline & 100 & 0,0226 & 0,2702 & 0,3302 & 0,5942 & 0,7419 \\
\hline
\end{tabular}

(1) Referente à porosidade total do solo

(2) Referente à CMAP do solo

fósforo aplicada ao solo, deu-se aumento do coeficiente de difusão do elemento, em virtude da saturação progressiva da superfície de adsorção, o que resultou no aumento da concentração de fósforo na solução do solo, como inclusive constataram também Mahtab et al. (1971), Villani (1995) e Santos et al. (2005). Maiores valores da diferencial $\mathrm{dC}_{1} / \mathrm{dC}$ induzem maior gradiente de fósforo, que ocorre com maior intensidade em solos arenosos que apresentam menor adsorção. De acordo com Novais \& Smith (1999), o aumento do grau de saturação da superfície adsorvente, ocasionado pelo incremento da dose de fósforo aplicada, implica em redução da 
Tabela 3. Equações de regressão relacionando o fluxo

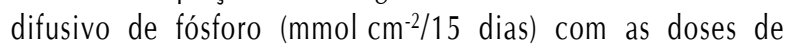
fósforo nos diversos níveis de umidade, dentro dos solos utilizados

\begin{tabular}{|c|c|c|c|}
\hline Solo & $\begin{array}{c}\text { Umidade } \\
(\%)^{1}\end{array}$ & Equações & $\mathbf{R}^{2}$ \\
\hline \multirow{8}{*}{$\mathrm{LV}_{1}$} & 10 & $Y=0,09366$ & \\
\hline & 20 & $Y=0,002887 X^{* * 0,906861}$ & 0,998 \\
\hline & 40 & $Y=0,006987 X^{\star \star} 0,801158$ & 0,998 \\
\hline & 60 & $Y=0,008396 X^{* * 0,805276}$ & 0,995 \\
\hline & 70 & $Y=0,008805 X^{\star \star 0,838813}$ & 0,995 \\
\hline & 80 & $Y=0,011358 X^{\star * 0,826732}$ & 0,997 \\
\hline & 90 & $Y=0,013159 X^{\star * 0,817374}$ & 0,998 \\
\hline & 100 & $Y=0,013063 X^{* * 0,844926}$ & 0,999 \\
\hline \multirow{8}{*}{$\mathrm{LVA}_{1}$} & 10 & $Y=0,001275 X^{\star \star 0,538395}$ & 0,899 \\
\hline & 20 & $Y=0,002776 X^{* * 0,692369}$ & 0,944 \\
\hline & 40 & $Y=0,005441 X^{\star * 0,804177}$ & 0,959 \\
\hline & 60 & $Y=0,006701 X^{\star *} 0,888372$ & 0,976 \\
\hline & 70 & $Y=0,006602 X^{* \star 0,940485}$ & 0,990 \\
\hline & 80 & $Y=0,012018 X^{\star * 0,887920}$ & 0,991 \\
\hline & 90 & $Y=0,014963 X^{\star * 0,872522}$ & 0,989 \\
\hline & 100 & $Y=0,013835 X^{* * 0,918152}$ & 0,994 \\
\hline \multirow{8}{*}{ LVdf } & 10 & $Y=0,001301 X^{* * 0,362623}$ & 0,897 \\
\hline & 20 & $Y=0,005454 X^{\star * 0,317105}$ & 0,832 \\
\hline & 40 & $Y=0,010593 X^{* * 0,337005}$ & 0,913 \\
\hline & 60 & $Y=0,011635 X^{\star \star 0,375077}$ & 0,973 \\
\hline & 70 & $Y=0,011796 X^{* * 0,452918}$ & 0,934 \\
\hline & 80 & $Y=0,012970 X^{* * 0,508359}$ & 0,993 \\
\hline & 90 & $Y=0,029654 X^{* * 0,425521}$ & 0,984 \\
\hline & 100 & $Y=0,026816 X^{* * 0,457134}$ & 0,994 \\
\hline \multirow{8}{*}{$\mathrm{LVA}_{2}$} & 10 & $Y=0,001262 X^{* * 0,552342}$ & 0,925 \\
\hline & 20 & $Y=0,003953 X^{\star \star 0,549679}$ & 0,952 \\
\hline & 40 & $Y=-0,0419695+0,000799523^{* *} X$ & 0,983 \\
\hline & 60 & $Y=0,008099 X^{\star \star 0,655898}$ & 0,989 \\
\hline & 70 & $Y=0,010801 X^{\star \star} 0,642467$ & 0,991 \\
\hline & 80 & $Y=0,012372 X^{* * 0,654856}$ & 0,988 \\
\hline & 90 & $Y=0,021775 X^{\star \star 0,591711}$ & 0,995 \\
\hline & 100 & $Y=0,017440 X^{* * 0,655279}$ & 0,998 \\
\hline \multirow{8}{*}{$\mathrm{LV}_{2}$} & 10 & $Y=0,003703 X^{* \star 0,164508}$ & 0,470 \\
\hline & 20 & $Y=0,004873 X^{\star * 0,437952}$ & 0,839 \\
\hline & 40 & $Y=0,005289 X^{* * 0,524808}$ & 0,956 \\
\hline & 60 & $Y=0,009213 X^{* * 0,479747}$ & 0,967 \\
\hline & 70 & $Y=0,009126 X^{* * 0,531206}$ & 0,962 \\
\hline & 80 & $Y=0,013335 X^{* * 0,497103}$ & 0,959 \\
\hline & 90 & $Y=0,021305 X^{\star * 0,454265}$ & 0,973 \\
\hline & 100 & $Y=0,021532 X^{* * 0,469676}$ & 0,980 \\
\hline
\end{tabular}

${ }^{1}$ Referente à porosidade total do solo

$\star \star$ : Significativo a $1 \%$ pelo teste $\mathrm{F}$

energia de ligação de fósforo com a superfície e, conseqüentemente, maior quantidade de fósforo ligada com menor energia. Com baixa saturação da superfície adsorvente, o fósforo é firmemente retido e, assim, menor quantidade de fósforo estará na forma lábil.

Comparando-se os valores entre os solos, verifica-se que o maior fluxo difusivo ocorreu na maior dose de fósforo aplicada (744 $\mathrm{mg} \mathrm{dm}^{-3}$ de P), correspondente a uma vez a CMAP, no $\mathrm{LVA}_{1}$ associado ao mais alto nível de umidade; nota-se ainda que os valores de fluxo difusivo foram muito baixos quando o fósforo não foi aplicado, principalmente nos níveis de umidade mais baixos. Acréscimos de fluxo difusivo muito maiores foram verificados entre os níveis 1 ( $0 \%$ da CMAP) e 2 (25\% da CMAP) de fósforo que entre os níveis 4 (75\% da CMAP) e 5 (100\% da CMAP), em todos os solos. Para as condições de umidade com $100 \%$ dos poros ocupados com água, o fluxo difusivo no $\mathrm{LV}_{1}$, com a dose mais elevada de fósforo (399 $\mathrm{mg} \mathrm{dm}^{-3} \mathrm{de} \mathrm{P}$ ), correspondeu a, praticamente, três vezes o valor observado no $\mathrm{LV}_{2}$, com uma dose de $1.172 \mathrm{mg} \mathrm{dm}^{-3}$ de P (Tabela 4). Para o $\mathrm{LVA}_{1}\left(744 \mathrm{mg} \mathrm{dm}^{-3} \mathrm{de}\right.$ $\mathrm{P}$ ), o fluxo difusivo foi mais de oito vezes superior ao encontrado no $\mathrm{LV}_{2}$, o que reflete a diferença no fator capacidade de $\mathrm{P}$ desses solos, motivada pela textura e mineralogia dos mesmos. Neste nível de umidade, também se pode observar que, quando a dose de fósforo é duplicada (de $99 \mathrm{mg} \mathrm{dm}^{-3}$ para $199 \mathrm{mg} \mathrm{dm}^{-3}$ de P), no $\mathrm{LV}_{1}$, a difusão aumenta mais do que quando se dobra a dose no $\mathrm{LV}_{2}$ (de $293 \mathrm{mg} \mathrm{dm}^{-3}$ para $586 \mathrm{mg} \mathrm{dm}^{-3} \mathrm{de} \mathrm{P}$ ), para o mesmo nível de umidade, indicando maior efetividade do aumento da dose de fósforo no fluxo difusivo no solo mais arenoso. Villani et al. (1993) encontraram comportamento semelhante, trabalhando com solos de diferentes texturas submetidos a doses de fósforo e níveis de umidade.

Os aumentos mais acentuados do fluxo difusivo nos solos mais arenosos, quando se aumentam as doses de P, comparados com os menores acréscimos nos solos mais argilosos, a despeito destes receberem doses bem mais elevadas, mostram que pequenas alterações no fator intensidade são conseguidas com altas doses de P nos solos argilosos. Segundo Novais \& Smyth (1999) e Rheinheimer et al. (2003), em razão do fator capacidade desses solos ser tão elevado, só se conseguem pequenas alterações no $\mathrm{P}$ na solução do solo com aplicação de doses muito elevadas de $\mathrm{P}$, que já não são mais econômicas.

De modo geral, os solos mais arenosos apresentaram maior fluxo difusivo que os solos de textura mais argilosa, o que era esperado, uma vez que a resistência dos solos arenosos a mudanças no fator intensidade de $\mathrm{P}$, é menor que a dos solos argilosos, mas, neste trabalho o $\mathrm{LVA}_{1}$, com $33 \mathrm{dag} \mathrm{kg}^{-1} \mathrm{de}$ argila e CMAP de $744 \mathrm{mg} \mathrm{dm}^{-3} \mathrm{P}$, apresentou maior fluxo difusivo que o $\mathrm{LV}_{1}$, com $13 \mathrm{dag} \mathrm{kg}^{-1}$ de argila e CMAP de $399 \mathrm{mg} \mathrm{dm}^{-3} \mathrm{P}$. Comportamento semelhante foi verificado entre o $\mathrm{LVA}_{2}$ e o LVdf, tendo o primeiro, com maior teor de argila, apresentado maior fluxo difusivo que o segundo. Isto pode estar relacionado à menor "energia de adsorção" (Tabela 1) verificada para o $\mathrm{LVA}_{1}$ e o $\mathrm{LVA}_{2}$, a despeito de apresentarem maior CMAP que o LV 1 e o LVdf. Para Holford (1980), solos com maior "energia de adsorção" convertem facilmente fósforo lábil em não-lábil, diminuindo, portanto, sua disponibilidade. Ao se combinarem essas duas características de sorção de $\mathrm{P}$, tem-se a capacidade tampão máxima, denominada, por Novais \& Smyth (1999) fator capacidade de P máximo $\left(\mathrm{FCP}_{\text {máx }}\right)$, dos solos estudados, chegando-se aos valores de 346, 431, 1.063, 769 e $1.453 \mathrm{~mL} \mathrm{~g}^{-1}$ para $\mathrm{LV}_{1}, \mathrm{LVA}_{1}, \mathrm{LVdf}, \mathrm{LVA}_{2}$ e $\mathrm{LV}_{2}$, respectivamente. $\mathrm{O} \mathrm{FCP}_{\text {máx }}$. é a curvatura obtida na isoterma de Langmuir, correspondente à diferencial $\mathrm{dx} / \mathrm{dc}$ quando c tende a zero. Observa-se que este índice pode explicar melhor a diferença de fluxo difusivo entre os solos. Na com- 
paração do $\mathrm{LV}_{1}$ com o $\mathrm{LVA}_{1}$, verifica-se que os valores de $\mathrm{FCP}_{\text {máx. }}$ dos dois solos são mais próximos que quando se comparam os valores de CMAP; também o FCPmáx. do $\mathrm{LVA}_{2}$ ( $\left.769 \mathrm{~mL} \mathrm{~g}^{-1}\right)$ é menor que o do $\operatorname{LVdf}\left(1.063 \mathrm{~mL} \mathrm{~g}^{-1}\right)$, o que pode explicar a ocorrência de maior fluxo difusivo no primeiro, a despeito do maior teor de argila e da mais elevada CMAP.

Os maiores valores de fluxo difusivo encontrados no $\mathrm{LVA}_{2}$ (Tabela 2) com maior teor de argila em relação ao LVdf, parecem encontrar justificativa na ausência de gibbsita no primeiro solo. Na literatura se encontram vários trabalhos que mostram a maior influência da goethita e da gibbsita no aumento da adsorção de fósforo em relação a outros minerais. As controvérsias encontradas confirmam a dificuldade de se estabelecer conclusões definitivas em relação aos processos de adsorção e dessorção e, conseqüentemente, de difusão do fósforo quando da ocorrência desses minerais no solo. Bahia Filho (1982), considerando a influência do componente mineralógico na disponibilidade de fósforo no solo, verificou que a goethita foi responsável por 97 e $86 \%$ das variações observadas na capacidade tampão máxima e na adsorção máxima, respectivamente. Almeida et al. (2003) também referem-se aos óxidos de ferro e alumínio como sendo os constituintes da fração argila que mais influenciam a adsorção de fósforo, sendo esta mais pronunciada em solos com predominância de goethita. Por outro lado, Fernández (1995) que obteve resultados em extrações sucessivas de fósforo com resina de troca aniônica sugere que é a gibbsita, e não a goethita, o óxido responsável pela restrição à dessorção do fósforo.

As equações de regressão que relacionam o fluxo difusivo de fósforo com as doses deste elemento nos cinco solos, encontram-se na Tabela 3. O modelo matemático de melhor ajuste aos dados experimentais correspondeu à equação potencial, indicando que, ao contrário do que se esperava pela equação do coeficiente de difusão de fósforo (Eq.2), a relação entre dI/dQ e o coeficiente de difusão nem sempre é linear, direta. O fluxo difusivo se elevou de forma curvilínea em todos os solos. No menor nível de umidade, no $\mathrm{LV}_{1}$, nenhum modelo se ajustou aos dados.

Influência do conteúdo volumétrico de água no fluxo difusivo

A difusão de um íon no solo está diretamente relacionada com o conteúdo volumétrico de água, conforme expressado na própria equação do coeficiente de difusão (Eq.2), uma vez que esta umidade determina a fração da área ou o volume de solo em que ocorre o fluxo difusivo. Uma maneira indireta da água afetar o coeficiente de difusão, seria sua influência no fator de impedância (Nye, 1979; Barraclough \& Tinker, 1981). A principal hipótese deste trabalho foi que a relação direta, linear, entre o conteúdo volumétrico de água do solo e o coeficiente de difusão do fósforo no solo, nem sempre se verifica, sendo variável com o solo.

Quando o conteúdo de água foi elevado, o fluxo difusivo de fósforo também aumentou para qualquer dose do elemento fornecido, em todos os solos (Tabelas 2 e 4). Mesmo quando não se adicionou fósforo ao solo, ainda se observou fluxo difusivo crescente com os níveis de umidade, exceto no $\mathrm{LV}_{1}$ na dose zero de fósforo, em que os valores de fluxo di-
Tabela 4. Equações de regressão relacionando o fluxo difusivo de fósforo com os conteúdos de água nos diversos níveis de fósforo, dentro dos solos utilizados

\begin{tabular}{|c|c|c|c|}
\hline Solo & Umidade $(\%)^{1}$ & Equações & $R^{2}$ \\
\hline \multirow{5}{*}{$\mathrm{LV}_{1}$} & 0 & $Y=0,008162$ & \\
\hline & 25 & $Y=-0,024386+1,37437^{* *} X$ & 0,968 \\
\hline & 50 & $Y=0,100203+2,05223^{* *} X$ & 0,946 \\
\hline & 75 & $Y=2,465188^{* *} X^{0,83642}$ & 0,912 \\
\hline & 100 & $Y=0,0748781+4,40428^{\star *} X$ & 0,985 \\
\hline \multirow{5}{*}{$\mathrm{LVA}_{1}$} & 0 & $Y=0,027697^{* \star} X^{0,99978}$ & 0,957 \\
\hline & 25 & $Y=4,412777^{* *} X^{1,76660}$ & 0,960 \\
\hline & 50 & $Y=15,759412^{* *} X^{2,32678}$ & 0,988 \\
\hline & 75 & $Y=24,459637^{* *} X^{2,06820}$ & 0,995 \\
\hline & 100 & $Y=25,753129^{* *} X^{1,83539}$ & 0,973 \\
\hline \multirow{5}{*}{ LVdf } & 0 & $Y=0,042482^{* *} X^{1,11805}$ & 0,904 \\
\hline & 25 & $Y=0,793595^{* *} X^{1,72657}$ & 0,989 \\
\hline & 50 & $Y=0,789527^{\star *} X^{1,42721}$ & 0,944 \\
\hline & 75 & $Y=0,803304^{* *} X^{1,45578}$ & 0,877 \\
\hline & 100 & $Y=1,541246{ }^{* *} X^{1,53860}$ & 0,964 \\
\hline \multirow{5}{*}{$\mathrm{LVA}_{2}$} & 0 & $Y=0,033526^{* *} X^{1,04268}$ & 0,946 \\
\hline & 25 & $Y=-0,0832410+1,1280^{\star \star} X$ & 0,991 \\
\hline & 50 & $Y=2,673485^{\star *} X^{1,55127}$ & 0,983 \\
\hline & 75 & $Y=3,544247^{* *} X^{1,33349}$ & 0,976 \\
\hline & 100 & $Y=3,622405^{* *} X^{1,17184}$ & 0,979 \\
\hline \multirow{5}{*}{$\mathrm{LV}_{2}$} & 0 & $Y=0,023400{ }^{* *} X^{0,68381}$ & 0,790 \\
\hline & 25 & $Y=0,579676{ }^{* *} X^{1,68215}$ & 0,985 \\
\hline & 50 & $Y=0,701736{ }^{\star *} X^{1,39544}$ & 0,915 \\
\hline & 75 & $Y=-0,0166652+1,0509^{* *} X$ & 0,973 \\
\hline & 100 & $Y=-0,0384511+1,1996^{* *} X$ & 0,967 \\
\hline
\end{tabular}

${ }^{1}$ Referente à CMAP dos solos

**: Significativo a $1 \%$ pelo teste $\mathrm{F}$

fusivo, no menor nível de umidade, não atingiram o mínimo necessário para permitir detecção pelos métodos analítico e instrumental utilizados. Na literatura, são encontradas referências propondo aumentar a dose de fósforo para compensar um teor de água menor ou vice-versa. Ruiz (1986b) refere-se à possibilidade de diminuição das doses de fósforo com o acréscimo do conteúdo de umidade do solo, de modo a manter o fluxo difusivo, enquanto Mahtab et al. (1971), considerando a relação entre o teor de fósforo e o conteúdo de água do solo, sugerem o aumento da quantidade de fósforo para compensar a diminuição do teor de água, visando à manutenção da difusão.

Maiores valores de fluxo difusivo foram observados nos solos mais arenosos, nos quais, o transporte de fósforo é favorecido, em comparação com os solos mais argilosos, com maior $\mathrm{FCP}_{\max }$. A elevada adsorção de fósforo desses últimos, provoca diminuição do fluxo difusivo que pode chegar a, praticamente, paralisar em conteúdos de água ainda elevados. A quantidade de água aplicada nos solos mais arenosos foi menor que aquela adicionada aos solos mais argilosos, em todos os tratamentos, de vez que a água foi aplicada como percentual do volume de poros e a porosidade calculada correspondeu a 48, 51, 60, 57 e 62\% para os $\mathrm{LV}_{1}, \mathrm{LVA}_{1}, \mathrm{LVdf}, \mathrm{LVA}_{2}$ e $\mathrm{LV}_{2}$, respectivamente (Tabela 1). De acordo com Novais \& Smyth (1999), os solos argilosos, com menor fator de impedância e maior interação íon-colóide, apresentam menor coeficiente de difusão para um mesmo conteúdo volumétrico de 
água, porém, se o potencial for o mesmo, a difusão será maior no solo argiloso, devido ao seu maior conteúdo volumétrico de água para a mesma energia de retenção.

Houve tratamentos em que 40 e $60 \%$ dos poros do solo foram ocupados com água. Nestes casos a umidade correspondeu aos valores iguais e superiores ao da capacidade de campo, podendo a umidade corresponder à porosidade total do solo, refletindo-se na saturação hídrica das amostras. Nessas condições de saturação, constatou-se que o fluxo difusivo foi superior em todos os níveis de fósforo e em todos os solos (Tabela 4). Com o aumento da umidade acima da capacidade de campo, os acréscimos no fluxo difusivo entre os níveis de umidade foram menores que os verificados com o aumento do conteúdo de água abaixo da capacidade de campo. Quando se comparam os níveis de umidade 1 (10\% dos poros ocupados com água) e 2 (20\% dos poros ocupados com água) nos vários solos, verifica-se que os aumentos de fluxo difusivo foram mais pronunciados que entre os níveis 7 ( $90 \%$ dos poros ocupados com água) e 8 (100\% dos poros ocupados com água); por exemplo, o fluxo difusivo foi 3,2, 6,7, 3,4, 2,5 e 8,0 vezes superior no nível de umidade 2 , em relação ao nível de umidade $1, \operatorname{nos} \mathrm{LV}_{1}, \mathrm{LVA}_{1}$, LVdf, $\mathrm{LVA}_{2}$ e $\mathrm{LV}_{2}$, respectivamente, para a maior dose de fósforo testada. Nos níveis de umidade 7 e 8 os valores foram muito próximos para os mesmos solos e dose de fósforo, verificando-se maiores aumentos quando se passa do nível 1 para o nível 2 de umidade que quando se comparam os níveis 7 e 8 de umidade.

Comparando-se os níveis 1 e 8 de umidade nos vários solos, registraram-se acréscimos do fluxo difusivo em todas as doses de fósforo; na maior dose de fósforo testada, os aumentos de fluxo difusivo deste elemento, quando se compararam os níveis 1 e 8 de umidade, foram de 10,95, 78,10, 36,00, 15,30 e 35,30 vezes nos $L V_{1}, L_{1} A_{1}, L V d f, L V A_{2}$ e $L V_{2}$, respectivamente.

As equações de regressão que relacionam o fluxo difusivo de fósforo com os conteúdos de água nos cinco solos encontram-se na Tabela 4. As equações ajustadas foram predominantemente potenciais, indicando que, ao contrário do que é comum na literatura (Eq.2), a relação entre o conteúdo volumétrico de água do solo e o coeficiente de difusão nem sempre é linear. O fluxo difusivo se elevou de forma curvilinear em todos os solos com o acréscimo do conteúdo volumétrico de água, o que apóia a hipótese de não-proporcionalidade entre o conteúdo volumétrico de água e o coeficiente de difusão de fósforo no solo; na dose zero de fósforo, no $\mathrm{LV}_{1}$, nenhum modelo se ajustou aos dados.

$\mathrm{Na}$ literatura, os trabalhos que relacionam a umidade do solo e a difusão são mais freqüentes com teores de água variando em uma faixa desde conteúdos de água muito baixos até a capacidade de campo, dando-se menos ênfase às condições de umidade que possam induzir o solo à saturação. Pelos dados deste trabalho, verificou-se que, embora em condições de saturação, o fluxo difusivo de fósforo ainda cresceu. $\mathrm{O}$ aumento da disponibilidade de fósforo em solos inundados tem sido encontrado em vários trabalhos que se referem às alterações dos fatores capacidade e intensidade $\mathrm{e}$ à difusão como responsáveis pelo suprimento de fósforo às raízes nestes solos (Basu, 1977; Khalid et al., 1977; Mello, 1991).

Neste trabalho, os maiores valores de fluxo difusivo foram encontrados nos conteúdos de água mais elevados e nos solos em que o fator capacidade foi menor. Turner \& Gilliam (1976) atribuíram o maior suprimento de P para arroz ao aumento da difusão deste elemento em solos inundados. Os autores observaram acréscimos de até dez vezes no coeficiente de difusão de $\mathrm{P}$ quando os solos foram saturados em relação aos níveis de umidade mais baixos, sendo pouco pronunciados os aumentos de fluxo difusivo nos solos de textura mais fina e baixos teores de fósforo.

\section{CONCLUSÕES}

1. O fluxo difusivo do fósforo sofreu influência da umidade do solo, sendo os maiores níveis os mais eficientes.

2. As doses de fósforo mais elevadas promoveram maiores valores de fluxo difusivo no solo.

3. Os atributos dos solos influenciaram o fluxo difusivo do fósforo.

4. A resposta à umidade e às doses de fósforo não foi linear, como esperado pela equação de difusão.

\section{LITERATURA CITADA}

Almeida, J.A.; Torrent, J.; Barron, V. Química de solos com carga variável. Piracicaba: ESALQ, 2003. 50p.

Azevedo, W.R.; Faquin, V.; Fernandes, L.A.; Oliveira Júnior, A.C. Disponibilidade de fósforo para o arroz inundado sob efeito residual de calcário, gesso e esterco de curral aplicados na cultura do feijão. Revista Brasileira de Ciência do Solo, Viçosa, v.28, p.995-1004, 2004.

Bahia Filho, A.F.C. Índices de disponibilidade de fósforo em Latossolos do Planalto Central com diferentes características texturais e mineralógicas. Viçosa: UFV, 1982. 178p. Tese Doutorado

Barber, S.A. Soil nutrient bioavailability: A mechanistic approach. New York: John Wiley \& Sons, 1995. p.330-338.

Barraclough, P.B.; Tinker, P.B. The determination of ionic diffusion coeficients in field soils. I. Diffusion coefficients in sieved soils in relation to water content and bulk density. Journal of Soil Science, Reading, v.32, p.225-236, 1981.

Basu, S.N. Effect of organic matter and initial $\mathrm{pH}$ value on phosphorus availability of submerged soil. Fertilizer Technology, Madison, v.14, p.376-378, 1977.

Braga, J.M.; Defelipo, B.V. Determinação espectrofotométrica do fósforo em extratos de solos e plantas. Revista Ceres, Viçosa, v.21, p.73-85, 1974.

Defelipo, B.V.; Ribeiro, A.C. Análise química do solo (metodologia). Viçosa: UFV, 1981. 17p. Boletim de Extensão, 29

EMBRAPA - Empresa Brasileira de Pesquisa Agropecuária. Serviço Nacional de Levantamento e Conservação de Solos. Manual de métodos de análise de solo. 2. ed. Rio de Janeiro: Embrapa-SNLCS, 1997. 212p. 
EMBRAPA - Empresa Brasileira de Pesquisa Agropecuária. Sistema Brasileiro de Classificação de Solo. Rio de Janeiro: Embrapa:CNPS, 1999. 412p.

Fernandes, B. Retenção e movimento de água no solo. Viçosa: UFV, 1967. 49p. Dissertação Mestrado

Fernández, R.I.E.J. Reversibilidade de fósforo não-lábil em diferentes solos, em condições naturais e quando submetidos à redução microbiológica ou química. Viçosa: UFV, 1995. 94p. Tese Doutorado

Holford, I.C.R. Effects of phosfhate buffer capacity on critical levels and relationship between soil test and labile phosphate in wheat growing soils. Australian Journal of Soil Research, Melbourne, v.18, p.405-414, 1980.

Jackson, M.L. Soil chemical analysis. New Jersey: PrenticeHall, 1958. 498p.

Kampf, N.; Curi, N. Argilominerais em solos brasileiros. In: Curi, N.; Marques, J.G.S.M.; Guilherme, L.R.G; Lima, J.M., Lopes, A.S.; Alvarez Venegas, V.H. (eds) Topicos em ciência do solo. Viçosa: SBCS, 2003. p.1-54.

Khalid, R.A., Patrick Jr., W.H.; Laune, R.D. Phosphorus sorption characteristics of flooded soils. Soil Science. Society of America Journal., Madison, v.41, p.305-310, 1977.

Mahtab, S.K.; Godfrey, C.L.; Swoboda, A.R.; Thomas, G.W. Phosphorus diffusion in soils: I. The effect of applied P, clay content and water content. Soil Science Society of America Proceedings, Madison, v.35, p.393-397, 1971.

Mello, J.W.V. Dinâmica de fósforo, ferro e manganês e disponibilidade de fósforo para o arroz em solos inundados. Viçosa: UFV, 1991. 212p. Tese Doutorado

Novais, R.F.; Kamprath, E.J. Parâmetros das isotermas de adsorção de fósforo como critério de recomendação de adubação fosfatada. Revista Brasileira de Ciência do Solo, Campinas, v.3, p.37-41, 1979.

Novais, R.F.; Smyth, T.J. Fósforo em solo e planta sob condições tropicais. Viçosa: UFV, 1999. 399p.

Nunes, F.N.; Novais, R.F.; Silva, I.R.; Gebrim, F.O.; São José, J.F.B. Fluxo difusivo de ferro em solos sob influência de doses de fósforo e de níveis de acidez. Revista Brasileira de Ciência do Solo, Viçosa, v.28, p.423-429, 2004.
Nye, P.H. Diffusion of ions and uncharged solutes in soils and clays. Advances in Agronomy, v.31, p.225-272, 1979.

Nye, P.H.; Tinker, P.B. Solute movement in the soil-root system. Oxford: Black Scientific publications, 1977. 342p.

Parfitt, R.L. Phosphate reactions with natural allophane, ferrihydrite and goethite. Journal of Soil Science, Oxford, v.40, p.359-369, 1989.

Raij, B. van; Quaggio, J.A.; Cantarella, H.; Ferreira, M.E.; Lopes, A.S.; Bataglia, O.C. Análise química do solo para fins de fertilidade. Campinas: Fundação Cargill, 1987. 170p.

Remer, W.; Schilling, G. Effect of the soil water regime on the diffusion coefficient of phosphate ions. Soviet Soil Science, London, v.13, p.110-114, 1981.

Rheinheimer, D. dos S.; Anghinoni, I.; Conte, E.; Kaminski, J.; Gatiboni, L.C. Dessorção de fósforo avaliada por extrações sucessivas em amostras de solos provenientes dos sistemas plantio direto e convencional. Ciência Rural, Santa Maria, v.6, p.1053-1059, 2003.

Ruiz, H.A. Efeito do conteúdo de água sobre o transporte de fósforo em dois latossolos. Viçosa: UFV, 1986a. 86p. Tese Doutorado

Ruiz, H.A. O transporte do fósforo na solução do solo. Revista. Cultura, Vitória, v.36, p.65-72, 1986 b.

Santos, G.A.; Dias Júnior, M.S.; Guimarães, P.T.G.; Furtini Neto, A.E. Diferentes graus de compactação e fornecimento de fósforo influenciando no crescimento de plantas de milho (Zea mays L.) cultivadas em solos distintos. Ciência Agrotécnica, Lavras, v.29, p.740-752, 2005.

Turner, F.T.; Gilliam, J.W. Increased P diffusion as an explanation of increased $\mathrm{P}$ availability in flooded rice soil. Plant and Soil, Dordrecht, v.45, p.365-377, 1976.

Vettori, L. Métodos de análises de solo. Rio de Janeiro: Ministério da Agricultura, 1969. 24p. Boletim Técnico, 7

Villani, E.M.A. Fluxo difusivo de fósforo influenciado por fontes e por tempo de contato do fósforo com o solo. Viçosa: UFV, 1995. 57p. Dissertação Mestrado

Villani, E.M.A.; Novais, R.F.; Barros, N.F.; Fontes, L.E.F.; Neves, J.C.L. Difusão de fósforo em solos com diferentes texturas e níveis de umidade. Revista Brasileira de Ciência do Solo, Viçosa, v.17, p.343-347, 1993. 